\title{
ELECTRIC-HYDROSTATIC DRIVE SYSTEMS AND THEIR APPLICATION IN INJECTION MOULDING MACHINES
}

\author{
Prof. Dr.-Ing. Siegfried HELDUSER \\ Institute for Fluid Power and Motion Control \\ University of Technology Dresden \\ D-01062 Dresden, Germany
}

\begin{abstract}
The aim of the research work was to reveal the potential advantages and challenges of the electric-hydrostatic drive system, a new direct pump control concept. Measurements of component efficiency have proved that hydraulic components have a very good efficiency compared with variable-speed electric motors. Therefore, the total efficiency of the electric-hydrostatic drive at high load cannot be expected to be noticeably better than that of the conventional drive system comprising an asynchronous electric motor and a variable displacement hydraulic pump. The major advantages of the new motor-pump concept are reduction of power losses and noise during part-load and during idling. Due to the high overload capability of rare-earth electric motors, the dynamic performance of the electric-hydrostatic drive can be compared to that of many standard variable displacement pumps. That was evaluated by performance tests of the clamp unit of a plastics injection moulding machine.

The electric-hydrostatic drive system increases the number of direct pump control concepts which a hydraulic project engineer can apply to design competitive hydraulic systems for customer applications.
\end{abstract}

\section{KEY WORDS}

Electric-hydrostatic drive, energy saving, pump efficiency, ease of use, injection moulding machine

\section{NOMENCLATURE}

$\alpha \quad$ pivoting angle

$\eta \quad$ efficiency

$\eta_{1} \quad$ total efficiency of the hydraulic pump

$\eta_{\text {vol }}$ volumetric efficiency of the hydraulic pump

$\eta_{\mathrm{m}-\mathrm{el}}$ total efficiency of the electric drive system

$\eta_{\text {ges }}$ total efficiency of the motor-pump unit

$\mathrm{M}_{1} \quad$ torque at pump shaft

$\mathrm{n}_{1} \quad$ speed at pump shaft

$\begin{array}{lll} & \mathrm{p}_{1} & \text { hydraulic system pressure } \\ & \mathrm{P}_{\mathrm{el}} & \text { electric input power } \\ & \mathrm{P}_{\text {hy }} & \text { hydraulic power of pump outlet } \\ & \mathrm{P}_{\mathrm{V}} & \text { power loss } \\ & \mathrm{Q}_{\text {soll }} & \text { flow demand signal } \\ & \mathrm{Q}_{1} & \text { pump output flow } \\ & \mathrm{Q}_{1 \mathrm{~L}} & \text { pump leakage flow } \\ & \mathrm{t} & \text { time } \\ \mathrm{Nm} & \mathrm{U} & \text { voltage } \\ \mathrm{min}^{-1} & \mathrm{~V}_{1} & \text { pump displacement volume }\end{array}$

bar

$\mathrm{kW}$

$\mathrm{kW}$

$\mathrm{kW}$

$1 / \mathrm{min}$

$1 / \mathrm{min}$

$1 / \mathrm{min}$

$\mathrm{s}$

V

$\mathrm{cm}^{3}$ 
$\mathrm{V}_{\mathrm{A}}$ pressurised oil volume

$\mathrm{W}_{\mathrm{el}}$ electric input energy

$\mathrm{w}_{\mathrm{p}} \quad$ pressure demand signal

$x$ rod position

$\dot{\mathrm{x}} \quad$ rod velocity

\section{Introduction}

Fluid power and motion control systems have fostered and enabled automation and productivity increase of stationary and mobile machinery during the last few decades. Some of the major advantages offered by hydraulic systems are compact and light-weight design due to high power density, fast response and good controllability of movements as well as cost effective, direct linear actuation with hydraulic cylinders. The designer of hydraulic systems has the choice between different well established and proven system structures: power and motion control can be based either on valve control, direct pump control or common pressure rail technology; he is offered reliable and advanced electrohydraulic components and system products at reasonable cost by globally acting suppliers.

But mainly driven by social forces, challenging requirements are gaining increased importance: environmental acceptance of technologies, energy consumption in regard of manageable operating expense as well as ease of installation and use /1/. Hydraulic power and motion control systems, unfortunately, need attention to cope with these requirements; they do not always operate with a superior total efficiency, although hydraulic components, e. g. pumps and actuators, are optimised to achieve a very high efficiency at widely changing operating parameters. Non-negligible power losses may occur, for instance, in restricted flow areas of valves, manifold blocks or pipes as well as during idling $12,3 /$. Even in hydraulic systems with direct pump control, power losses are not always negligible, because idling losses are not eliminated and in part-load both asynchronous electric motor and hydraulic pump do not operate with best efficiency.

An outstanding improvement in the grade of energy use in hydraulic power and motion control technology is achieved by the electric-hydrostatic actuator because input power is well adjusted to the power required at the actuators and idling losses are eliminated. Another advantage is its noise reduced operation compared to conventional hydraulic systems, with the pump running constantly at about $1500 \mathrm{rpm}$. This innovative development comprises a variable speed electric motor that drives a fixed displacement hydraulic unit and a hydraulic motor or cylinder. The paper discusses its performance features and the application in the clamping unit of an injection moulding machine.

\section{Energy Saving Potential of Speed Controlled Motor-Pump Units}

Direct pump control is the most energy efficient way to control power and movements in hydraulic systems. Figure 1 shows three basic options. The first one, the combination of a variable displacement pump and an asynchronous electric motor is the most common structure applied today.

\begin{tabular}{|c|c|c|}
\hline $\begin{array}{l}\text { Induction Motor with } \\
\text { Variable Pump }\end{array}$ & $\begin{array}{l}\text { Speed Controlled Induction } \\
\text { Motor with Variable Pump }\end{array}$ & $\begin{array}{l}\text { AC-Servomotor with } \\
\text { Constant Pump }\end{array}$ \\
\hline $\begin{array}{l}\text { - constant speed } n_{1} \text {, } \\
\text { - flow and pressure control } \\
\text { with } \Delta V_{1} \text {, } \\
\text { - low efficiency at } P<P_{\max } \text {; }\end{array}$ & $\begin{array}{l}\text { - speed control, } \\
\text { - flow and pressure control with } \\
\Delta n_{1} \text { and } \Delta V_{1} \text {, } \\
\text { - better efficiency at } P<P_{\max } \text {, } \\
\text { - no idling losses }\left(n_{1}=0\right) \text {, } \\
\text { - low noise }\left(n_{1}<n_{1} \text { max }\right) \text {; }\end{array}$ & $\begin{array}{l}\text { - speed control, } \\
\text { - flow and pressure control } \\
\text { with } \Delta n_{1} \text {, } \\
\text { - better efficiency at } P<P_{\max } \\
\text { - no idling losses }\left(n_{1}=0\right) \text {, } \\
\text { - low noise }\left(n_{1}<n_{1} \max \right) ;\end{array}$ \\
\hline
\end{tabular}

Figure 1: Control of hydraulic power by direct pump control 
Flow and pressure are controlled via the pump displacement. Static and dynamic characteristics of the pump displacement control have been improved to such a degree that the performance of this type of direct pump control system can, to some extend, be compared with proportional valve control. A significant proof of this has become evident at the plastics exhibition $K^{\prime} 98$ : Variable pumps with electrohydraulic overcenter displacement control are more and more replacing loadsensing control in plastic injection moulding machines. Further improvements regarding the grade of energy use can be achieved by combining the variable displacement pump with a variable speed electric motor, the second structure shown in figure 2 . Movements and forces in a machine are still controlled via the pump displacement, speed adjustments allow to reduce power losses and noise; during part-load total efficiency can be improved by reducing motor speed and onstroking the pump. investigated parameter range, both axes are comparable (66 1/min $\Leftrightarrow 1500 \mathrm{~min}^{-1}$ ) with sufficient accuracy. The total efficiency $\eta_{\text {ges }}$ of both systems is about the same at high pressure $p_{1}$ and flow $Q_{1}$. Some difference can be noticed at part-load operation, when the electrichydrostatic drive offers an improved efficiency $\eta_{\text {ges }}$. This is basically due to the good efficiency $\eta_{1}$ of the fixed displacement pump; this unit offers the best efficiency at all operating parameters; the ACservomotor and drive unit do not have a similarly good efficiency $\eta_{\mathrm{m} \text {-el }}$ as the hydraulic components or the asynchronous electric motor. The efficiency $\eta_{1}$ of the variable-displacement pump is mainly dependent on the stroke and not so much on the operating pressure $\mathrm{p}_{1}$; power losses at part-load are higher than for the asynchronous motor. Therefore, it may be worthwhile
The third part shows the electrichydrostatic drive: A speed controlled servomotor drives a fixed displacement pump. Control of machine operating parameters, actuator position, speed or force is transferred from the hydraulic pump to the servomotor; speed control replaces displacement control. With regard to the grade of energy use and low noise this is the most favourable structure: power losses are minimised, fixed displacement pumps can have a better efficiency than those with variable-displacement, and lownoise displacement principles, e. g. internal gear, can be used.

Figure 2 shows a comparison of a displacement controlled swash plate axial piston pump, driven by a standard asynchronous motor as well as a speed controlled bent axis pump driven by an ACservomotor. Both pumps have $\mathrm{V}_{1}=45 \mathrm{~cm}^{3}$ max. displacement volume. Electric power input $P_{e l}$, torque $M_{1}$, speed $n_{1}$, flow $Q_{1}$ and pressure $p_{1}$ were measured for efficiency calculation. The efficiency of the electric-hydrostatic system is shown versus speed $n_{1}$, whilst for the displacement-controlled pump it has to be shown versus flow $\mathrm{Q}_{1}$.

Due to the fact that the volumetric efficiency $\eta_{1 \text { vol }}$ of the bent axis pump is above $95 \%$ for most of the
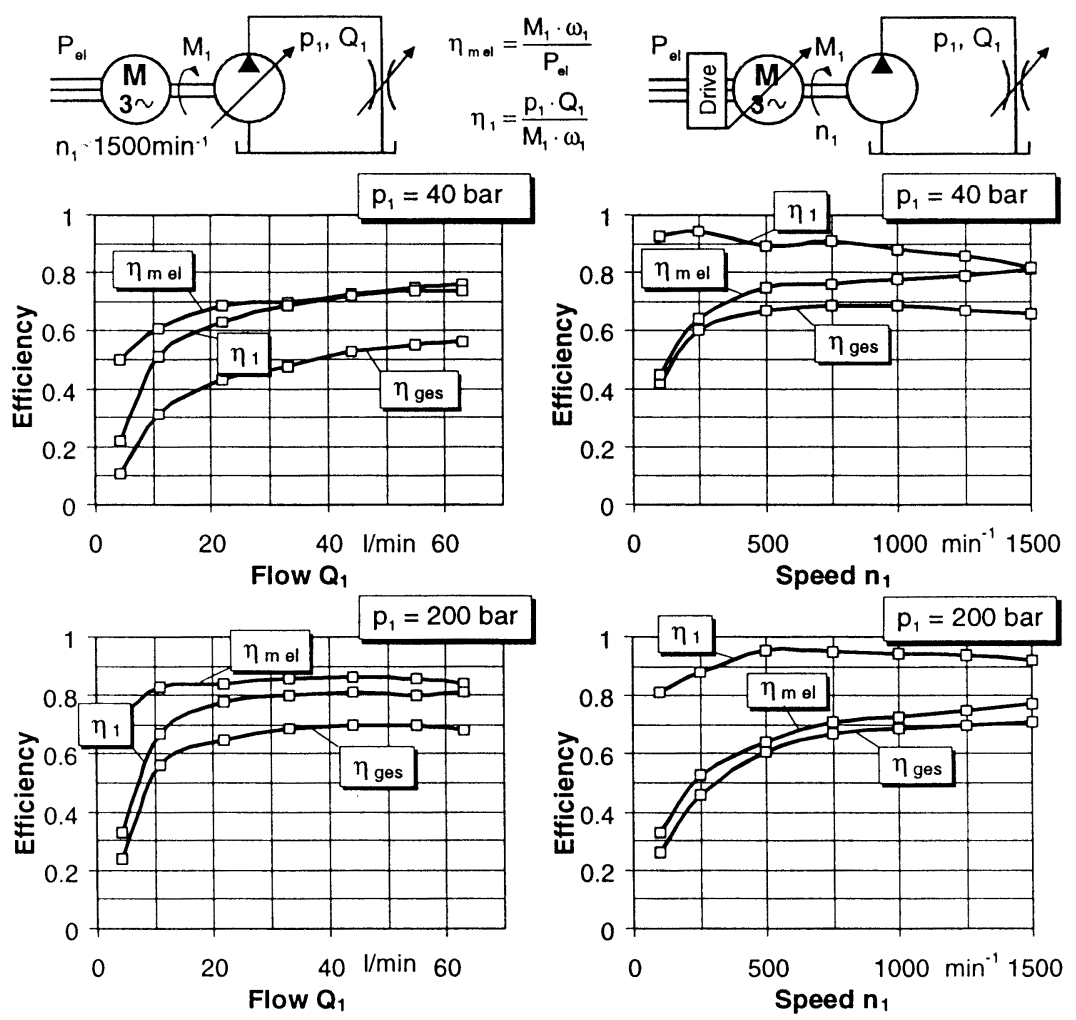

Figure 2: Efficiency comparison for a variable-displacement and a speed-controlled hydraulic pump

combining a variable-displacement pump with a variable-speed electric motor, if a low energy consumption is aimed for.

The advantages of the electric-hydrostatic drive in energy saving seem to be not so dominant, comparing component efficiency only. Therefore, it was compared with a standard system with displacement control in a generalised typical duty cycle, shown in figure 3 . The 
electrical input power $\mathrm{P}_{\mathrm{el}}$ was measured as well as the hydraulic output power $\mathrm{p}_{1} \cdot \mathrm{Q}_{1}$. Energy consumption was calculated from $\mathrm{W}_{\mathrm{el}}=\sum\left(\mathrm{P}_{\mathrm{el}} \cdot \Delta \mathrm{t}_{\mathrm{i}}\right)$.

The displacement controlled drive running this duty cycle for one hour consumed $8.4 \mathrm{kWh}$, the speed controlled system, however, consumed $6.6 \mathrm{kWh}$ only. For the duty cycle defined, this is a reduction of energy consumption that can never be achieved by improvements in component efficiency. The greatest energy saving potential for the electric-hydrostatic system is during idling: the energy needed for stand-by operation of the hydraulic pump with displacement control and the asynchronous electric motor is the main source of energy losses in this comparison.
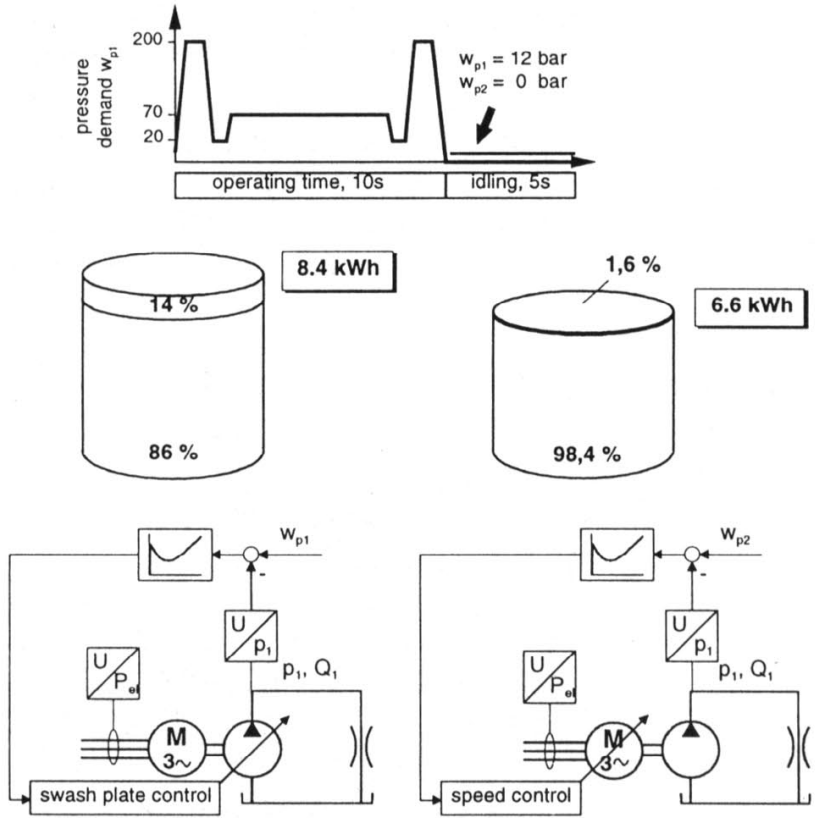

Figure 3: Energy consumption of a displacementcontrolled and a speed- controlled drive during one hour for a specified duty cycle

From the point of view of energy saving, the application of an electric-hydrostatic drive is highly dependent on the duty cycle of a machine. If a machine has to perform cyclic movements with some idling, this drive concept allows a reduction of operating expense by saving electric energy. A typical application may be a plastics injection moulding machine, where the hydraulic system may be idling for some time after the injection cycle before the clamp has to be opened. In duty cycles, when the hydraulic pump is running at corner power during most of the time, the electric-hydrostatic drive may offer no advantages, justifying the additional investment cost.
3 Investigation of hydraulic pumps for speed variable operation

\subsection{Steady-state pump performance}

Hydraulic pumps driven at variable speed have to cope with requirements and operating conditions that are quite different from their normal operation with only very limited speed variations. For example, the speed controlled pump has to work at very low speed under maximum as well as minimum pressure or has to reverse speed. Furthermore, gap compensation, e.g. in vane pumps and in gear pumps, can be a problem; because the pump should have a linear characteristic flow versus speed.
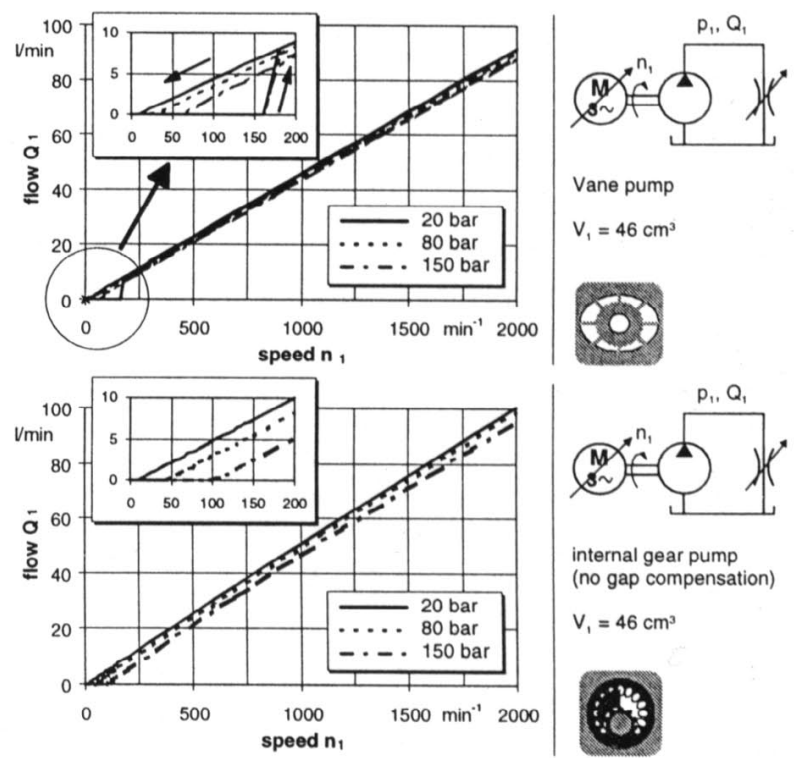

Figure 4: Flow versus speed characteristics of a vane pump and an internal gear pump

Figure 4 shows two flow-versus-speed characteristics. The vane pump, in the upper part of the figure, initially does not deliver any flow for speeds $n_{1}<160 \mathrm{~min}^{-1}$, because the vanes, initially pressed against the cam ring by centrifugal forces only, stick in the rotor. If the speed is reduced from high values below $\mathrm{n}_{1}<160 \mathrm{~min}^{-1}$ and pressure $p_{1}$ is above a certain value, e.g. 60 bar, the vanes remain pressed against the cam ring and the pump operates perfectly, even at very low speed $n_{1}$. The internal gear pump investigated has no gap compensation and, therefore, no non-linear effects. But the lag of gap compensation causes high internal leakage: at 150 bar, e.g., the pump starts to deliver flow not before a minimum speed of $\mathrm{n}_{1}=100 \mathrm{~min}^{-1}$ is reached. Pump leakage has an importance influence in speed controlled operation: if a static load has to be carried, leakage losses have to be compensated by a 
small speed of the pump. And this may cause the pump to heat up. However, the elimination of the gap compensation can be reasonable method to make an internal gear pump fairly suitable for speed-variable operation.

\subsection{Endurance Testing}

The loads on the drive mechanism of a hydraulicdisplacement unit due to variable-speed operation may cause increased wear. For instance the hydrodynamic percentage contact area in plain bearings (e.g. piston shoes, valve plate) may not work or there may be an unacceptable mechanical stress in the drive mechanism. Therefore, several pumps (piston-type, gear-type and vane-type) were endurance tested for about $100 \mathrm{~h}$ with a special duty cycle of $60 \mathrm{~s}$ : The pumps were tested in a closed loop pressure control mode at about full flow and at zero flow; the duty cycle includes very high speed changes during the first $45 \mathrm{~s}$, followed by a period with no flow $\mathrm{Q}_{1}$ output under high pressure; during the last $15 \mathrm{~s}$ the pumps operated at a constant speed of $\mathrm{n}_{1}=300 \mathrm{~min}^{-1}$ and at $\mathrm{p}_{1}=10$ bar to cool the pump and the AC-servomotor. During pressure cycling, speed changes at the pump shaft reached values of $\mathrm{dn} / \mathrm{dt}=31,000 \mathrm{~min}^{-1} / \mathrm{s}$, and system pressure changes went up to $\mathrm{dp} / \mathrm{dt}=1200 \mathrm{bar} / \mathrm{s}$. After $30 \mathrm{~s}$ the pump outlet port was blocked and the trapped oil volume was held at a constant pressure of $p_{1}=70 \mathrm{bar}$. To compensate internal leakage the pump had to run at a minimum speed During the last $15 \mathrm{~s}$ the motor-pump system was idling, as mentioned before. When the pressure $p_{1}$ is reduced from $p_{1}=70$ bar to $p_{1}=10$ bar, the direction of speed $n_{1}$ is reversed for a short period of time because the pump decompresses the trapped oil volume.

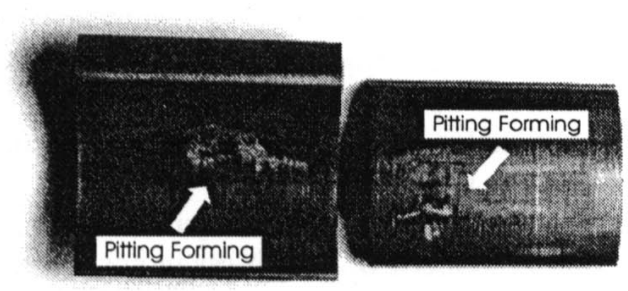

Figure 5: Tightness of an internal gear pump after $100 \mathrm{~h}$ of endurance testing with a speed controlled drive

As an example, figure $\mathbf{5}$ shows the wear pattern of a gap-compensated internal gear pump. Due to high pressing between hardened tooth tips and the sealing wedge made of brass alloy some material was removed from the sealing wedge. Pittings occurred in the contact area between the wedge and the pinion as well as the ring gear. This wear is probably caused by the balancing of the gap compensation. However, this is a specific wear pattern for the pump type investigated and a $100 \mathrm{~h}$ testing can only provide first indications of wear.

\section{Injection Moulding Machine with Electric- Hydrostatic Drive for the Clamp}

Plastic injection moulding machines are required for the mass production of plastic parts. About 50,000 machines are being produced annually world-wide representing an estimated market volume of at least 3,400 mill. Euro per year. Hydraulically operated European machines have been the technological leader with high productivity for many years. During the last few years mainly Japanese and American manufacturers have introduced electromechanically operated machines. The main arguments are: average energy consumption about $50 \%$ less, better environmental acceptance (no mineral oil, less cooling energy) $/ 5 /$.

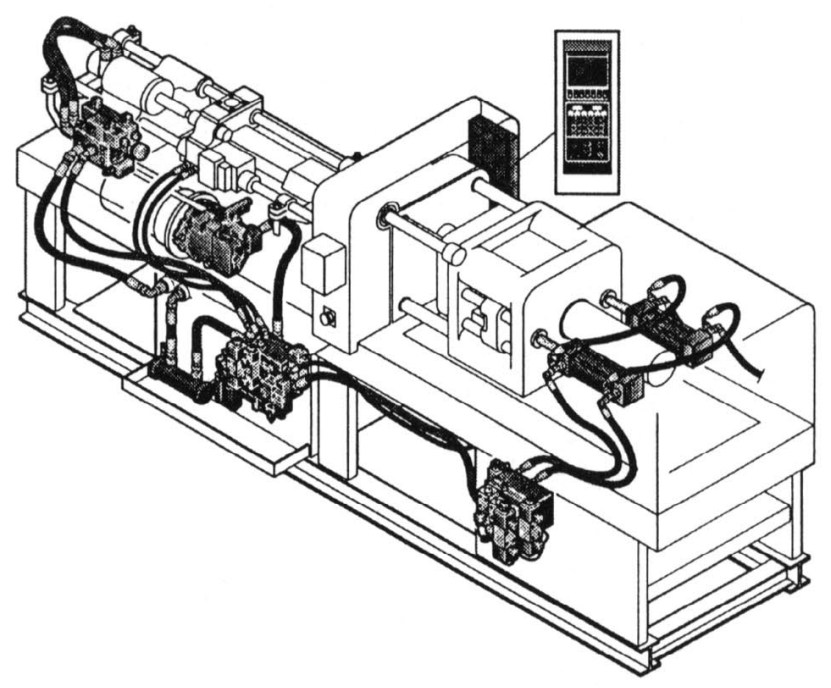

Figure 6: All-hydraulic plastic injection moulding machine

However, five of the six axes of an injection moulding machine perform linear movements, figure 7. Hydraulic drives are much better suitable for this type of machine than electro-mechanics is. But energy consumption of the hydraulic system should be reduced to remain competitive. The electric-hydrostatic drive makes if possible to reduce power losses and noise during holdon pressure (pressure control without actuator movement), back pressure or cooling of the plastic part (pump rotation may be stopped). 


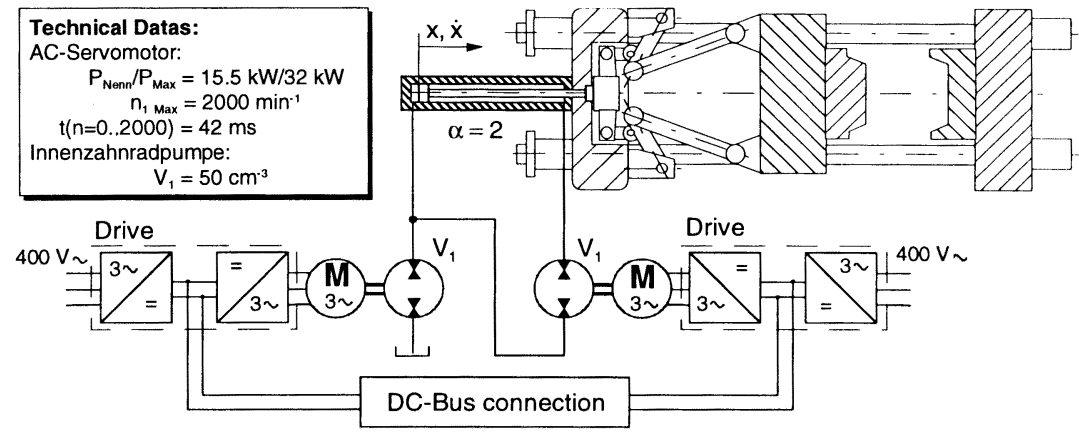

Figure 7: $\quad$ Toggle operated clamp of a plastics injection moulding machine with electric-hydrostatic actuator

At the Institute of Fluid Power and Motion Control of Dresden University of Technology, the clamping unit of a plastics injection moulding machine with $1600 \mathrm{kN}$ clamping force was equipped with an electrichydrostatic drive system. The structure of the system is shown in figure 7. The hydraulic circuit is based upon two independent motor-pump units comprising an internal gear pump and an AC-servomotor. The advantage of this system is that it has two degrees of freedom for the control of the clamp movement and that the two smaller AC-servomotors are less expensive and have a better dynamic performance than one big motor. Furthermore, with two electric-hydrostatic units it is possible to control the other movements of the machine, too. The new hydraulic system with electric-hydrostatic drives has been designed in such a way that it should not exceed the cost of the conventional hydraulic system of the machine currently applied.

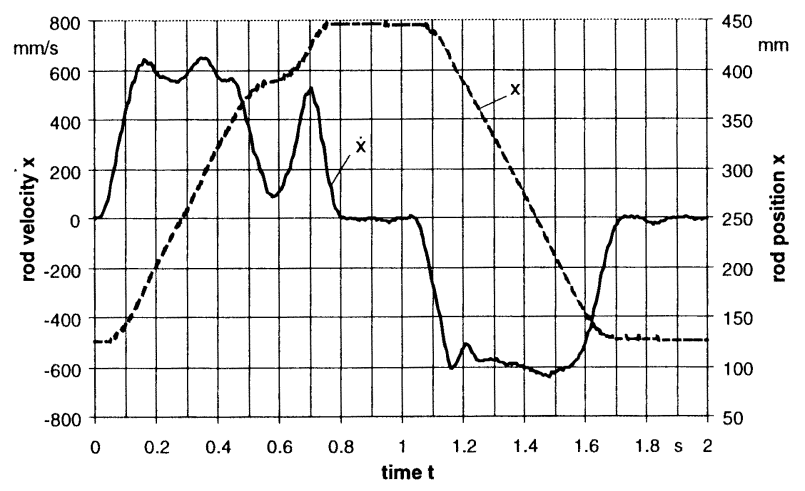

Figure 8

Dry-cycle time (Euromap 6) of the plastics injection moulding machine shown in fig. 6

The AC-servomotors are air-cooled, have a rated power of $15.5 \mathrm{~kW}$ and can be overloaded up to $32 \mathrm{~kW}$. Both motors have a separate drive. The DC-busses of both drives are coupled to allow exchange of braking energy. During the injection phase both pumps can work in parallel so that a max. injection power of $64 \mathrm{~kW}$ is available in the machine.
An important criterion of the comparison of different drive systems in plastic injection moulding machines is the dry cycle time according to the EUROMAP 6 standard. The dry cycle time is the time required to close the clamp (not including the mould protection phase), to build-up clamping force and to open the mould again. The stroke $\mathrm{x}$ of the hydraulic cylinder that operates the toggle of the clamp is $315 \mathrm{~mm}$. Test results are shown in figure 8 The dry cycle time is $1.9 \mathrm{~s}$ with the max. rod velocity of about $800 \mathrm{~mm} / \mathrm{s}$. This is a very competitive value for this size of machines. Further improvements of about $0.25 \mathrm{~s}$ seem to be achievable by reducing dead times in the machine controller.

\section{References}

1. Helduser, S., Innovationen im Maschinenbau durch fluidtechnische Komponenten und Systeme,

Ölhydraulik \& Pneumatik No. 6, 1996, pp. 380-395

2. Helduser, S. and Rühlicke, I., Elektro-hydraulische Antriebssysteme mit drehzahlveränderbaren Pumpen,

AiF Research Report No. 25/B 9953, 1996

3 Kazmeier, B. and Feldmann, D.G., Ein neues Konzept für einen kompakten elektrohydraulischen Linearantrieb,

1. Internationales Fluidtechnisches Kolloquium, Aachen 1998, pp. 345-358

4. O'Bryan, J., Seibert, G., Brushless motor drives injectors hydraulics,

Hydraulics \& Pneumatics, October 1991

5. Robers, T., Analyse des Betriebsverhaltens von vollelektrischen gegenüber hydraulisch angetriebenen Spritzgießmaschinen basierend auf Vergleichsmessungen, Dissertation, RWTH Aachen, 1995 